\title{
La primera reforma educativa liberal y su implementación en el Establecimiento de Jurisprudencia. Distrito Federal, 1833-1834
}

Mónica Hidalgo-Pego

\section{RESUMEN}

El artículo tiene como finalidad examinar la aplicación de las reformas educativas liberales en el Establecimiento de Jurisprudencia inaugurado el 5 de diciembre de 1833. Para contextualizar el estudio se hace referencia a los proyectos educativos ensayados entre 1821 y 1832, y se da cuenta de los principales decretos emitidos para la organización de los establecimientos profesionales. El examen de la documentación permite observar los cambios habidos en la enseñanza y conocer los fondos con que contaba la institución, así como valorar los alcances y limitaciones del primer ensayo educativo liberal a través de un estudio de caso.

Palabras clave: Reforma educativa, Distrito Federal, Establecimiento de Jurisprudencia, enseñanza, financiamiento, México. 


\section{A primeira reforma educativa liberal e sua implementação no Estabelecimento de Jurisprudência. Distrito Federal, 1833-1834}

\section{RESUMO}

$\mathrm{O}$ artigo tem como finalidade examinar a aplicação das reformas educativas liberais no Estabelecimento de Jurisprudência inaugurado no dia 5 de dezembro de 1833. Para contextualizar o estudo faz-se referência aos projetos educativos ensaiados entre 1821 e 1832, e se verifica os principais decretos emitidos para a organização dos estabelecimentos profissionais. A análise da documentação permite observar as mudanças ocorridas no ensino e conhecer os fundos com que contava a instituição, assim como valorizar os alcances e limitações do primeiro ensaio educativo liberal através de um estudo de caso.

Palavras chave: Reforma educativa, Distrito Federal, Estabelecimento de Jurisprudência, ensino, financiamento, México.

\section{The first liberal educational reform and its implementation in the School of Jurisprudence in Mexico, Federal District, 1833-1834}

\section{ABSTRACT}

The purpose of the article is to analyze the implementation of the liberal educational reforms in the School for Jurisprudence inaugurated on December 5, 1833. In order to contextualize the study, reference is made to the educational projects tested between 1821 and 1832, and the main decrees issued for the organization of professional establishments are reported. The inspection of the documentation allows us to observe the changes that have taken place in education and to know the funds that the institution had at its disposal, as well as to assess the scope and limitations of the first attempt of liberal education through a case study.

Key words: educational reform, Federal District, School of jurisprudence, teaching, financing of education, Mexico. 


\section{Introducción}

Como en el México de hoy, la educación también formó parte de las preocupaciones de los gobernantes del siglo XIX, por ello, entre 1823 y 1832 se impulsaron varios proyectos de carácter nacional con el objetivo de construir un sistema de instrucción pública, sin embargo, no lograron concretarse, no obstante, en aquellas entidades con "una fuerte orientación federalista" se crearon institutos literarios - Chihuahua y Jalisco (1826), Oaxaca (1827), Estado de México (1828), Zacatecas (1832) - los cuales contribuyeron a la creación del pretendido sistema a nivel estatal. Así, en los estados donde se abrió un instituto, nos dice Rosalina Ríos (1994), éste no quedaba como una entidad aislada sino dentro de un sistema, de una estructura, pues los planes educativos generalmente examinaron todos los aspectos que convenían a la mejor atención de la educación. "Se hablaba de la gratuidad y la uniformidad de la instruccion publica; de la primera, segunda, tercera y hasta, en el caso de Jalisco, cuarta enseñanza; se definían los establecimientos para cada uno de esos niveles y, además, se ordenaba, invariablemente, la creación de una Dirección General de estudios o Junta Directiva" (Ríos, 1994: 25).

Mientras esto sucedía en las entidades federativas, en los colegios y en la Universidad de la capital de la república, las variaciones introducidas eran mínimas, ya que se continuaban impartiendo los mismos saberes y se seguían sus antiguas constituciones, pero hacía finales de 1833, las cosas tomaron un nuevo rumbo con la promulgación en octubre de ese año de un conjunto de decretos cuya finalidad era reformar la educación en el Distrito y territorios de la Federación; dicho ensayo, a diferencia de los anteriores, si pudo ponerse en práctica, aunque circunscrito a la ciudad de México.

La historiografía sobre el siglo decimonónico ha escrito varias páginas sobre ese ensayo educativo dando luces sobre su contenido ideológico y político o sobre lo sucedido en la Nacional y Pontificia
Universidad de México (Sánchez, 2008: 365-406; Pavón, 2013: 61-81; Alvarado, 2003: 167-182, y Ríos, 2016: 121-149), pero sobre los seis establecimientos creados a partir de la reforma, la atención prestada ha sido sumamente escasa. Por ello debemos destacar los esfuerzos realizados por Cristian Rosas, quien se ha dedicado a trabajar tres de esas instituciones: ciencias médicas, ciencias físicas y matemáticas (Rosas, 2015), así como ciencias eclesiásticas (Rosas, 2019: 71-106). Ambos trabajos permiten observar mediante el estudio de los profesores, alumnos, cátedras, finanzas e incluso becas, los cambios, permanencias y avatares experimentados en dichos establecimientos.

Considero que el camino seguido por Rosas Íñiguez es adecuado, pues sólo estudiando lo sucedido en cada establecimiento podrá conocerse con mayor profundidad la dimensión de las transformaciones acometidas por los reformadores del $33 \mathrm{y}$ su grado de aplicación. Siguiendo esta línea de estudio, el presente escrito tiene como finalidad examinar lo ocurrido en el Establecimiento de Jurisprudencia abierto en el edificio del ex Colegio de San Ildefonso, haciendo en lo posible una comparación con los otros establecimientos trabajados. Asimismo, el texto busca advertir sobre los alcances y límites del primer ensayo educativo liberal través de un estudio de caso.

La exposición se divide en seis apartados, en el primero se presenta un panorama general de las propuestas educativas planteadas en 1821, 1830 y 1832; en el segundo se exponen los principales decretos emitidos en 1833 que hacen referencia a los seis establecimientos creados. A partir del tercer apartado, el texto entra de lleno en el examen del Establecimiento de Jurisprudencia, así se da cuenta de los preparativos para su inauguración, de la enseñanza impartida, de los catedráticos, de los alumnos y de sus finanzas.

Antes de comenzar es necesario advertir que las fuentes documentales sobre el Establecimiento de Jurisprudencia son escasas, a diferencia, por ejemplo, 
de las existentes para los dos primeros establecimientos estudiados por Rosas. ${ }^{1}$ Por tal motivo, para el análisis de la institución jurídica debió recurrirse a otras fuentes como las Memorias de los secretarios de Relaciones Interiores y Exteriores, los periódicos de la época y los textos de José María Luis Mora, sin embargo, sus escritos deben tomarse con algunas reservas, pues su punto de vista responde a la del hombre que se encargó de planear las reformas y de desdeñar los esfuerzos educativos precedentes. Así pues, la información obtenida sobre el establecimiento resulta un tanto fragmentada, empero, ha sido posible dar algunas luces sobre lo acontecido en su interior.

\section{Primeros intentos de reforma, 1823-1832}

El 4 de octubre de 1824, el segundo Congreso General Constituyente promulgó la Constitución Federal de los Estados Unidos Mexicanos; en su título III, sección quinta, se estableció que entre las facultades exclusivas del Congreso se encontraban: impulsar la educación, erigir colegios de marina, artillería e ingeniería, así como establecimientos dedicados a la instrucción de las ciencias naturales, exactas, políticas, morales, lenguas y artes "sin perjudicar la libertad que tienen las legislaturas para el arreglo de la educacion pública en sus respectivos estados" (Constitución, 2005: 366).

La consigna de impulsar la enseñanza plasmada por los congresistas en la carta magna no resultaba una primicia, pues desde el último tercio del setecientos, los ilustrados españoles habían ensayado algunas reformas, aunque ninguna vislumbraba la creación de un sistema de instrucción pública. La construcción del mencionado sistema tanto en la Península como en los territorios de ultramar comenzó a gestarse en 1809, cuando la corona quedó acéfala por el cautiverio de Fernando VII a manos de los franceses y alcanzó su concreción, al menos en el papel, en las Cortes gaditanas de 1814 (Tanck, 1991: 3-34), pero con el retorno del rey todo lo tratado en Cádiz fue suspendido. Pocos años después, durante el trienio liberal (1820-1823), se promulgó el 29 de junio de 1821, el Reglamento General de Instrucción Pública, en el cual se legisló también para la Nueva España.

Con la firma del acta de Independencia el reglamento no se aplicó, no obstante, sus postulados generales, e incluso algunos particulares, sirvieron de base en la ardua y complicada tarea de construir un sistema de instrucción pública para la incipiente nación mexicana. Dichos postulados fueron los siguientes: la enseñanza costeada por el Estado será pública, uniforme y gratuita, la instrucción se dividirá en primera, segunda y tercera, ${ }^{2}$ se creará una Dirección General de Estudios, el financiamiento de la educación será público y los saberes modernos y uniformes (Reglamento, 1821: 3).

En México, los intentos para crear el pretendido sistema comenzaron en 1823 durante el gobierno del Supremo Poder Ejecutivo, este órgano presentó un proyecto de reglamento, al que le siguieron otros ensayos en 1826 y $1827,{ }^{3}$ pero ninguno logró avanzar debido a la inestabilidad política y económica que aquejaba al país. Además de los ensayos señalados, Lucas Alamán, quien desde su puesto como ministro de Relaciones había efectuado algunas propuestas para reformar la enseñanza, dedicó en su Memoria del 12 de febrero de 1830, un apartado para hablar sobre los establecimientos de instrucción del Distrito. $\mathrm{Al}$ referirse a la universidad y los colegios indicó los siguiente:

\footnotetext{
${ }^{1}$ Se consultó el Archivo de la Escuela de Jurisprudencia en busca de información, pero no se encontró nada sobre el establecimiento. Tampoco hay registro en el Fondo Colegio de San Ildefonso.

${ }^{2}$ La primera enseñanza era general e indispensable, consistía en leer y escribir, reglas elementales de la aritmética y catecismo. La segunda enseñanza servía de preparación para dedicarse a estudios más profundos y la tercera habilitaría para ejercer una profesión.

${ }^{3}$ El contenido de estos planes puede consultarse en Ramos, 1994.
} 
Tenemos varios establecimientos dedicados á la instruccion, y no tenemos un plan regular para ella: por su defecto se invierten todos los años sumas considerables en este ramo, sin que resulte la correspondiente utilidad. Con solo algunas variaciones, este importante punto que hubiera debido de llamar de preferencia la atencion, desde el momento de la independencia, permanece casi bajo el mismo pie en que se hallaba en el sistema colonial [...] Por tales causas, sigue la juventud careciendo de muchos ramos esenciales de instruccion de que no hay cátedras, mientras que otras se repiten innecesariamente en todos los Colegios, y continua asistiendo á los cursos de ceremonia de la Universidad empleando en ellos un tiempo que podría aprovechar mas útilmente (Memoria, 1830: 409).

Los inconvenientes descritos por Alamán lo llevaron a proponer un plan, el cual se reducía, según sus propias palabras, a "quitar lo superfluo y establecer lo necesario" (Loc. cit.). Para ello, cada colegio debía dedicarse a un ramo de enseñanza y la educación debía tener directrices homogéneas. La instrucción la dividió en cuatro ramos: ciencias eclesiásticas, con sede en el seminario conciliar; literatura clásica y derecho de las ciencias políticas y económicas en San Ildefonso, donde se eliminarían las cátedras comunes al seminario; ciencias físicas y matemáticas en Minería, donde ya se estudiaban, añadiéndole algunos ramos generales no relacionados con la actividad minera; ciencias médicas en el colegio de San Juan de Letrán, trasladando a él las cátedras aisladas de cirugía y anatomía del hospital de Jesús; las ciencias naturales se ubicarían en un establecimiento producto de la unión entre el jardín botánico y el museo nacional. Por último, indicaba que se prescindiría de las lecciones impartidas en la universidad, bastando para la graduación los cursos dictados en los colegios (Memoria, 1830: 41 y 43). Con esta reforma la universidad quedaba convertida en una instancia certificadora de saberes, pero ya no en una institución docente.
Lucas Alamán también habló de la creación de una Dirección General de Estudios como se había propuesto en el reglamento de 1821, así como de los caudales a utilizar para la educación, en primera instancia se contaría con los fondos propios de cada colegio y las cátedras dotadas, en segunda, con los recursos de las cátedras universitarias, en tercera con los capitales del colegio de Santos y del Instituto Nacional y, finalmente, con el peculio del colegio de San Gregorio, al cual no había dado destino (Memoria, 1830: 42). Si bien el ministro no habló en ningún momento de crear un fondo de instrucción pública, es evidente que esa era su intención.

En la Memoria de 1831, Alamán hizo referencia a la formación de una comisión integrada por individuos de ambas cámaras para trasformar sus ideas en un proyecto de ley, empero, no se dio ningún paso adelante (Memoria, 1831: 47-48). Sobre el proyecto del ministro, Mora opinó que éste tenía muchos defectos, pues nada se decía sobre el destino de la universidad, no se afianzaba un fondo para costear la educación, ni se incrementaba el ya existente (Briseño et al., 1994b: vol. 2, 458).

En 1832 se elaboró un nuevo plan, el cual retomaba lo relacionado con la creación de una dirección general: en cuanto a la enseñanza, no se tomaban en cuenta las observaciones de Alamán, ya que como sucedió con planes anteriores, los colegios seguirían dando los mismos saberes. Por tanto, Lucas Alamán fue el primero en plantear y reunir en un mismo proyecto tres elementos de suma relevancia, la dedicación de cada colegio a un ramo específico de enseñanza, la creación de una dirección general y la construcción de un fondo para financiar la instrucción, pese a lo dicho por Mora. El siguiente proyecto educativo se pondría en marcha en octubre de 1833, aunque desde septiembre se comenzó a trabajar en él, este ensayo recogió con sus respectivas modificaciones, los aspectos arriba mencionados.

En el siguiente apartado se dará cuenta de lo que se conoce como la Reforma Educativa de 18331834 conformada por un conjunto de decretos. No 
se pretende reproducir el contenido de todos ellos, sino presentar de forma general los relativos a los seis establecimientos.

\section{La instrucción pública en el Distrito. Breve acercamiento a las leyes de 1833-1834}

El encargado de instrumentar las reformas fue el vicepresidente Valentín Gómez Farías en sustitución del presidente Antonio López de Santa Anna, quien una vez asumida la presidencia el 1 de abril de 1833, se retiró a su hacienda de Manga de Clavo, Veracruz, argumentando motivos de salud, aunque Michael Costeloe (1996: 368) considera que se apartó para dejar a los liberales presentar sus reformas. A su regreso, las reformas emprendidas por Farías se mantuvieron hasta el 31 de julio de 1834, fecha en que el presidente emitió, a través de la Secretaría de Relaciones, una circular donde ordenaba la supresión de las leyes educativas de 1833, el regreso de la instrucción a su estado anterior y la suspensión de los establecimientos creados, reponiendo los anteriores; el único que logró sobrevivir fue el de ciencias médicas, como observó Cristian Rosas.

Para elaborar el nuevo plan para el Distrito y territorios de la Federación, Farías instituyó el 20 de septiembre de 1833, una junta o Comisión del Plan de Estudios presidida por él e integrada por Juan José Espinosa de los Monteros como vicepresidente, Manuel Eduardo Gorostiza como secretario y, como vocales, Andrés Quintana Roo, José María Luis Mora y Bernardo Couto. ${ }^{4}$

Cumplir con la tarea encomendada requería conocer el estado actual de los colegios que formarían parte del sistema de instrucción pública, con esta idea en mente la junta decidió efectuar visitas a cada institución tomando en cuenta los siguientes aspectos: educación, enseñanza y método; San Ildefonso fue visitado el 5 de octubre. Al finalizar las inspecciones se concluyó, nos dice Mora, que la educación era de tipo monacal, la enseñanza desarticulada de las "necesidades comunes y fuera de la marcha social" y los métodos para trasmitir los conocimientos sólo tenían un orden, el de elegir a un autor con 50 o 100 años de antigüedad, cuyos saberes se exponían y sustentaban aún en contra de la evidencia (Briseño et al., 1994b: 460-464). Y para remediar los males de las instituciones educativas, la comisión se planteó tres objetivos: " 1 , destruir cuanto era inútil o perjudicial a la educación y enseñanza; $2^{\circ}$, establecer ésta en conformidad con las necesidades determinadas por el nuevo estado social; $3^{\circ}$, difundir entre las masas los medios más precisos e indispensables de aprender" (Briseño et al., 1994b: 465).

La comisión comenzó a reunirse a partir del 24 de septiembre y concluyó sus sesiones el 23 de octubre, es decir nueve días después de la expedición de la primera ley de instrucción pública; a dicha ley le sucedieron otras cinco en el mismo mes (19, 23, 24 y 26) y una más el 19 de diciembre. En 1834 la actividad no cesó, expidiéndose siete documentos más, tres en enero $(9,15,25)$, uno el 10 de febrero, dos en abril (21 y 23) y otro el 2 de julio. La emisión de este último decreto se efectuó en condiciones distintas, no sólo porque Santa Anna había reasumido el poder, sino también por la supresión, el 23 de abril, de las facultades otorgadas por el congreso al gobierno para hacerse cargo de la instrucción pública y por los cambios de miembros en la dirección general, quedando únicamente Gómez Farías y Quintana Roo e integrándose a ella personajes adeptos al mandatario como José María Tornel y Germán Bonilla.

En la primera ley emitida el 19 de octubre, la Secretaría de Relaciones informó sobre la autorización dada al gobierno por parte del congreso general - en este órgano recaía la facultad de manejar la instrucción pública - para arreglar la educación en todos sus ramos. La segunda ley promulgada el

\footnotetext{
${ }^{4}$ Antes de formar la comisión, ya se habían tomado dos medidas importantes, el 9 de abril se decretó que los colegios de San Ildefonso, San Juan de Letrán, San Gregorio y el Seminario Conciliar quedaban facultados para conceder los grados de bachiller en filosofía, teología y derecho. El 12 de octubre se dispuso la clausura del Colegio de Santos.
} 
mismo día ha sido considerada como la más radical por ordenar la supresión de la Universidad de México, no obstante, ya existía un antecedente en el país, pues en 1825 el estado de Jalisco había cerrado la Universidad de Guadalajara para dar paso a un instituto. También se indicó la creación de una Dirección General de Instrucción Pública para el Distrito y territorios de la Federación y se anunció su composición y facultades. La dirección quedó conformada por los integrantes de la junta redactora del plan de estudios, a ella se sumó Juan de Dios Rodríguez Puebla, a quien se le ha señalado como miembro de la junta, pero al revisar la documentación de la misma, este personaje no aparece en ningún momento. Por último, se habló del administrador general de los fondos de educación pública, de sus atribuciones, así como de los ecónomos o mayordomos para cada establecimiento (Dublán, 1876: 565-566).

La tercera ley fue expedida el 23 de octubre, consta de seis capítulos, en el primero se dio a conocer el número de establecimientos de instrucción pública, su denominación y las cátedras a impartir en cada uno. ${ }^{5}$ Se les llamó establecimientos con la finalidad de no sentar un precedente que permitiera a los colegios reclamar el uso y abuso de las rutinas establecidas en ellos (Briseño et al., 1994b: 473). Los capítulos II y III hablan de los directores, subdirectores y profesores, así como de sus obligaciones y sueldos. En el IV se da orden a los estudios, se indica la duración de los cursos y se consignan las asignaturas previas para cada tipo de estudios. El V está dedicado a los grados académicos de doctor y el VI a disposiciones generales (Dublán, 1876: 571-574).

La cuarta ley correspondiente al 24 del mismo mes consignó y puso a cargo de la dirección general los gravámenes, fondos y fincas de las siguientes instituciones: el convento de San Camilo, el hospital y templo de Jesús con las fincas urbanas que pertenecían al conde de Monteleone; el antiguo y nuevo hospital de Belém, el hospital de Santo Tomás y su huerta; el edificio de la inquisición aplicado a la Academia de San Carlos por la ley del 20 de mayo de 1831; el templo y convento del Espíritu Santo, los ocho mil pesos que por el artículo $5^{\circ}$ de la ley del 1 de mayo de 1835 se entregaron al ayuntamiento para establecimiento de escuelas; los seis mil pesos asignados por la ley del 28 de enero de 1828 para gastos del instituto de ciencias, literatura y artes, asi como los tres mil pesos concedidos por esa ley para las escuelas lancasterianas y, finalmente, la imprenta establecida en el hospicio de pobres para mantener dicho establecimiento (Dublán, 1876: 574-575) .

La sexta ley del día 26, creaba entre otras cosas una escuela primaria para niños en cada uno de los establecimientos de estudios mayores; la séptima, emitida el 19 de diciembre, ordenaba que el Establecimiento de Ciencias Médicas reemplazara en sus atribuciones a la Facultad de Medicina. Por último, debe incluirse la novena ley del 9 de enero de 1834, la cual disponía que los exámenes de abogados sólo podrían presentarse ante la junta de profesores del Establecimiento de Jurisprudencia, presidida por el director o vicedirector, quedando habilitados los estudiantes aprobados para ejercer la abogacía en los tribunales de la Federación (Dublán, 1876: 576, 654, 659).

Hasta aquí el recorrido relativo a los decretos donde se veían involucrados los seis establecimientos. Después de la última ley expuesta se emitieron otras, no obstante, éstas se dictaron después del cese de las facultades otorgadas por el Congreso al Ejecutivo, de estas se dará cuenta más adelante.

\section{Los preparativos para la inauguración del establecimiento}

La apertura de los seis establecimientos demandó efectuar de manera previa diferentes adecuaciones,

\footnotetext{
${ }^{5}$ Los establecimientos creados y su sede fueron los siguientes: estudios preparatorios en el Hospital de Jesús, estudios ideológicos y humanidades en el convento de San Camilo, jurisprudencia en el Colegio de San Ildefonso, ciencias físicas y matemáticas en el Colegio de Minería, ciencias médicas en el convento de Belén y ciencias eclesiásticas en el Colegio de San Juan de Letrán.
} 
así como nombrar a las autoridades. Para el gobierno del quinto establecimiento, es decir el de Jurisprudencia, fue designado como director el licenciado Juan José Espinosa de los Monteros, y como subdirector el doctor Simón de la Garza y González, individuo que conocía bien el colegio por haber sido catedrático y vicerrector, entre otros cargos, ello lo convertía en un buen auxiliar del director.

Las demás acciones llevadas a cabo para poner en marcha el establecimiento quedaron consignadas en el informe presentado por Espinosa al director de la dirección general de instrucción Manuel Eduardo Gorostiza el 16 de abril de 1834. La petición fue emitida por la dirección el 15 de abril en respuesta a la solicitud del secretario del Despacho de Relaciones Interiores y Exteriores, quien debía informar al Superior Gobierno el estado de la instrucción pública. Dichas noticias debieron presentarse en enero, pero como señala Gorostiza, no había sido posible por las muchas ocupaciones de los miembros de la dirección y por el corto tiempo de funcionamiento de los establecimientos. Asimismo, indicó que al momento de redactar el informe solamente se tenían ideas incompletas y aún no validadas por la experiencia.

Pese a lo argumentado, el documento entregado por Espinosa proporciona algunas noticias sobre los arreglos, cambios y progresos del Establecimiento de Jurisprudencia, los cuales se irán conociendo a lo largo del texto. Por el momento, debe señalarse que para llevar a cabo la apertura fue necesario efectuar algunas reparaciones al edificio, empero faltó habilitar el refectorio y los espacios destinados para la impartición de cursos, tampoco se pudo abrir la escuela de primeras letras ordenada en la ley del 26 de octubre de 1833 (BUT, GB, JMLM: f. 241).

El cambio más representativo sin duda fue la modificación de los saberes. En primer lugar, se realizó la supresión de las tres cátedras de filosofía y las dos de teología existentes en el ex colegio ildefonsiano. En segundo lugar, se agregaron nuevas cátedras a la única asignatura de derecho preexistente, jurisprudencia, donde se daba derecho canónico y derecho civil, la finalidad de esta medida fue la de proporcionar a los alumnos una educación sólida y completa.

Terminadas las adecuaciones, el establecimiento abrió sus puertas el jueves 5 de diciembre de 1833 en el edificio del hasta entonces Nacional Colegio de San Ildefonso; ese mismo día hizo lo propio el de ciencias eclesiásticas y dos días antes el de estudios preparatorios, mientras ciencias fisicas y matemáticas debió esperar hasta el 2 de enero (Rosas, 2015: 154).

\section{Financiamiento}

Para emprender las reformas planeadas por los reformadores del 33 resultaba indispensable contar con el dinero suficiente para el sostenimiento de las dependencias erigidas, de los profesores y alumnos, así como la compra de libros, instrumentos, gabinetes, etcétera. Para ello, como ya se indicó en un aparatado anterior, los decretos establecieron la creación de un fondo de instrucción conformado con los bienes pertenecientes a diferentes instituciones, así como los de los colegios existentes en ese momento.

Gorostiza, al entregar su informe al Superior Gobierno en abril de 1834, dio varias noticias sobre los fondos de instrucción pública y su administración, aquí interesa resaltar lo relativo al importe del producto del fondo, lo aportado por el ex Colegio de San Ildefonso y los gastos. El fondo tenía un monto aproximado de 223830 pesos, 4 reales y 9 granos anuales provenientes de la hacienda pública, de colegiaturas anuales, del ayuntamiento, de las casas de Monteleone, del hospital de Jesús y sus fincas, de las casas de la Universidad, el Colegio de Santos, las fincas y capitales de San Gregorio, los conventos de San Camilo y Belém, el hospital de naturales y los colegios de San Juan de Letrán, Minería y San Ildefonso. Los gastos totales de instrucción eran de 191 419 pesos, de esa cantidad se debían destinar para los seis establecimientos 143590 pesos por concepto de sueldos, pensiones de gracia, mantenimiento del 
culto, escuelas anexas a ellos, inspección y gastos de las mismas, así como los desembolsos extraordinarios correspondientes a reparaciones y habilitación de los edificios, lo cual alcanzaba la suma de 30000 pesos (El Indicador de la Federación Mexicana, 1834: 29, 33-34).

El informe exhibió en números redondos la aportación hecha por cada entidad, San Ildefonso aportó 13555 pesos. Pero, ¿de dónde provenían los fondos del colegio? ¿Cuánto se gastó en la manutención del Establecimiento de Jurisprudencia? Según el balance general de instrucción pública presentado por el administrador general, Pedro Fernández del Castillo, el 2 de junio de 1834, los productos del colegio alonsiaco correspondían a los siguientes rubros: fincas urbanas 3350 pesos, fincas rústicas 8000 pesos aproximadamente, ${ }^{6}$ réditos de capitales impuestos 1090 y réditos de fundaciones 1195 pesos (AGN, JIP, exp. 11, f. 246).

El administrador también presentó un presupuesto general sobre las cantidades que de manera aproximada se necesitan en un año para sueldos, gastos ordinarios y extraordinarios de los seis establecimientos, escuelas ya creadas y culto público (AGN, JIP, vol. 11, f. 230). La cantidad ascendía a 185407 pesos, 1 real, 6 granos, ${ }^{7}$ es decir 5952 pesos, 1 real, 6 granos menos de lo indicado por Gorostiza en abril, sin poder precisarse por el momento las razones por la cuales difería la cantidad.

La cifra exacta que el Establecimiento de Jurisprudencia requería para su sostenimiento anual no se conoce con exactitud, pues algunos gastos como los relacionados con la manutención de los alumnos fueron registrados tomando en cuenta la suma de los estudiantes de todos los establecimientos, no obstante, se pueden presentar algunas cifras tentativas. Entre sueldos de autoridades y catedráticos debían pagarse en total 7400 pesos, divididos de la siguiente manera: 2000 para el director, 1500 para el vicedirector y 1200 a cada profesor, dichas cantidades habían sido estipuladas en los decretos y efectivamente los salarios mensuales se liquidaron sobre esos montos. Otros sueldos correspondían a los honorarios de dos médicos equivalente a unos 36 pesos, 300 para el mayordomo o ecónomo, 160 para mozos, empleados de cocina, aseo y servicio de los estudiantes, 2720 para 17 alumnos de dotación, es decir de becas de particulares, más 4155 para alimentos de aproximadamente 32 alumnos de paga, 770 por limpieza, alumbrado y otros sueldos y 829 de gastos ordinarios del culto privado y público de la capilla. El total de las remuneraciones, considerando que durante el año se mantuvieran los 49 alumnos calculados, era de 16370 pesos, 7 reales, 6 granos, cantidad que excedía lo aportado por el colegio de San Ildefonso.

Para solventar los gastos expuestos, el establecimiento, según lo estipulado por Fernández, contaba con 22551 pesos, 4 reales, 6 granos contabilizados desde el mes de noviembre y hasta el 2 de junio de 1834, así pues, la cantidad excedía el monto aportado inicialmente por San Ildefonso, ello se explica si se toma en cuenta que el Establecimiento de Jurisprudencia contó también con ingresos provenientes de la hacienda pública y de colegiaturas, sumados a los réditos de fincas y rendimiento de capitales. ${ }^{8}$

Los egresos en ese mismo periodo habían sido de 9899 pesos, 7 reales, 1 grano, usados en sueldos, gastos ordinarios y gastos extraordinarios por la compra de muebles y libros. Según estas cuentas, Jurisprudencia tenía a su favor 12653 pesos, 11 granos, demostrando

\footnotetext{
${ }^{6}$ Las fincas urbanas correspondían a varias casas con sus accesorias asentadas en las calles de Montealegre, Acequia, Regina, Chapitel de Montealegre y Colegio Cordobanes de Cristo. Se sabe que la finca rústica era la hacienda de Yerejé en Michoacán.

${ }^{7} 12$ granos equivalen a 1 real y 8 reales a un peso. Tales medidas comenzaron a utilizarse desde el siglo XVI en Nueva España y perduraron hasta 1846.

${ }^{8}$ La hacienda pública había contraído un adeudo de 6133 pesos, 2 reales, 8 granos con San Ildefonso, de esta cantidad había saldado al 1 de noviembre 2333 pesos, 2 reales y 6 granos. La deuda provenía de los 4000 que la hacienda pública se había comprometido a dar al colegio para su fomento en el presupuesto anual del 28 de enero de 1828.
} 
así una aparente solvencia económica, empero, en la última cuenta presentada por el administrador general el 6 de octubre, se observa que hasta el 31 de julio, cuando se suspendió el plan de instrucción pública, se habían quedado a deber cuatro meses de sueldo a las autoridades y catedráticos del establecimiento, al director se le adeudaban 666 pesos, 5 reales, 4 granos, al vicedirector 500, a seis catedráticos 400 por cada uno y a otros tres 356 , la diferencia estaba dada por que entre el 1 de abril y el 9 de mayo se habían finiquitado 44 pesos a cada uno, todo ello sumaba 4634 pesos, 2 reales, 9 granos (AGN, JIP, vol. 11, f. 231). No se sabe con exactitud el motivo de la deuda, sin embargo, pueden tenerse en cuenta algunos factores como el atraso en los pagos de la hacienda pública, los réditos aún no recuperados para 1837 correspondientes a la hacienda de Yerejé y los adeudos contraídos con anterioridad por el colegio de San Ildefonso, los cuales seguían vigentes al momento de entregar sus caudales al fondo de instrucción.

Los adeudos del colegio contabilizados anualmente reportaban los siguientes montos: 200 pesos a Manuela Revilla Orozquieta por el principal de 4000 pesos al 5\%; 80 al poseedor de una capellanía fundada sobre unas casas del colegio de Cristo con un principal de 1600 pesos al 5\%; 365 por las misas estipuladas por el fundador de dicho colegio; 795 pesos 4 reales a Agustín de Eguía por los réditos de 13269 pesos al 6\% sobre la hacienda de Acamilpa, más 725 pesos, 4 reales calculados al $6 \%$ por la cantidad de 12092 al mismo individuo, correspondientes a una partida de mulas vendidas al contado. Esta deuda ascendía a 2176 pesos, 8 reales. A ella deben sumarse 11188 pesos, 5 granos que se debían a los catedráticos antiguos y otros empleados del colegio. Ambas cantidades dan como resultado 13365 pesos, 9 granos. La deuda, por tanto, excedía el sobrante exhibido por el administrador general. Para saldar la cuenta, Fernández sugirió tomar el dinero de los fondos de instrucción pública reunidos durante la vigencia del plan, o de los caudales aún no devueltos y sin aplicación especial después del decreto de julio, pues por lo expresado en ese mismo decreto, ya se habían restituido a los colegios sus fondos (AGN, JIP, vol. 11, f. 31 r.), desafortunadamente no sabemos si se llevó a cabo la liquidación y si fue así, cuándo sucedió.

La falta de solvencia económica no fue exclusiva del Establecimiento de Jurisprudencia, lo mismo ha sido observado por Cristian Rosas para el de Ciencias Eclesiásticas, contrastando con el Establecimiento de Ciencias Físicas y Matemáticas donde gracias al apoyo de diferentes zonas mineras la institución disfrutó de una economía mucho más estable (Rosas, 2015: 134).

\section{Cátedras, exámenes, autores y textos}

En el decreto emitido el 23 de octubre de 1833 se consignaron las materias a impartir en cada uno de los establecimientos, en el caso del establecimiento jurídico, las cátedras debían ser las siguientes: derecho natural de gentes y marítimo, derecho político constitucional, derecho canónico, derecho romano, así como primera y segunda de derecho patrio. Además de estas asignaturas debía impartirse ética, retórica y primera y segunda de latinidad (Dublán, 1876: 572). En la sesión de la comisión del 14 de octubre, Mora se había opuesto a la instauración de cátedras de latinidad, empero, los demás miembros aceptaron su inclusión. En cuanto a retórica, Quintana Roo dijo que ésta debía enseñarse, pero en su aplicación a la elocuencia forense (AGN, IPBA, caja 37, exp. 28, f. 311). Dicha cátedra, sin embargo, no tuvo cursantes desde la apertura del establecimiento como indicó Gorostiza en las noticias presentadas en su informe de abril de 1834, ello no sucedió exclusivamente en Jurisprudencia, pues como también comunicó el director de la dirección general tampoco había alumnos en las cátedras de historia natural y geología correspondientes al Establecimiento de Ciencias Físicas y Matemáticas (El Indicador de la Federación Mexicana, 1834: 33); ello se debió quizás al desinterés de los alumnos. 
El periódico El Fénix de la Libertad comenzó a publicar desde el 28 de noviembre las listas de los profesores nombrados para cada establecimiento donde se incluían también las cátedras asignadas a cada profesor. La última lista apareció el 26 de diciembre, ésta permite conocer a los catedráticos del Establecimiento de Jurisprudencia y sus respectivas cátedras (El Fénix de la libertad, 26/XII/1833, t. III, núm. 148: 2). Entre lo establecido en la ley y los estipulado en la lista se observa una diferencia, la cátedra de ética no fue contemplada por la dirección, aunque en el informe elaborado por Espinosa en abril de 1834, el director menciona la existencia de dicha cátedra, así como la sustitución del nombre de retórica por el de elocuencia del foro y la tribuna (BUT, GB, JMLM: f. 241). La clase de ética seguramente se introdujo para que los cursantes mantuvieran un buen comportamiento en sus prácticas de derecho.

La inclusión de cátedras de latinidad llama la atención, pues éstas iban en contra del principio de especialización dado a cada establecimiento, sobre dicha inserción Mora apunta que se debió a "una concesión necesaria al espíritu de cuerpo, que sobrevivió a la extinción de los antiguos colegios; ninguno quería aceptar esta supresión ni desistir de las antiguas ideas de pequeñas universidades, y reclamaba para la suya como si todavía estuviese existente, el aumento de cátedras y ramos de enseñanza" (Briseño et al., 1986b: 475).

Si lo dicho por Mora es cierto, las exigencias aludidas quizá provinieron de tres individuos, José María Estrada, Manuel Chávez y José María Guzmán, el primero había sido vicerrector de San Ildefonso en 1831 y catedrático de latín a partir del 14 de octubre de 1833, el segundo ya era catedrático de la misma materia desde 1830, así como maestro de aposentos y el tercero era rector al momento del cierre del colegio. Según Mora, Guzmán había solicitado "de la manera más activa y eficaz" ser colocado en "cualquier cosa", y gracias a su intervención se le había contratado donde quiso (Briseño et al., 1986b: 481). Sea cual sea la razón, lo cierto es que las cátedras siguieron dándose a pesar de ser un establecimiento dedicado a los estudios jurídicos.

El 15 de marzo de 1834 se dieron nuevas instrucciones referentes a las asignaturas, sin embargo, se desconoce cuándo se pusieron en práctica o si realmente se hizo, pues la información procede de un dictamen elaborado por el vicedirector Simón de la Garza sobre los puntos propuestos ante la junta de directores de los establecimientos para fijar las bases del reglamento del Establecimiento de Jurisprudencia (BUT, CB, JMLM: fs. 265-267). Y señalo el desconocimiento, debido a que el reglamento aún no se había enviado a la dirección de instrucción cuando su director Manuel Gorostiza presentó su informe al Superior Gobierno. ${ }^{9}$

En el segundo punto del proyectado reglamento se hablaba sobre la duración de las cátedras y su orden, así como de los exámenes. En cada cátedra se darían dos cursos con una duración de cinco meses cada uno, las cátedras de derecho se cursarían de ocho y media a nueve y media de la mañana en el siguiente orden: natural de gentes y marítimo, civil, canónico, político constitucional, primera de patrio y segunda del mismo derecho. Las de elocuencia y ética se impartirían de diez a once de la mañana, a la primera asistirían los cursantes de derecho natural de gentes y marítimo, y a la segunda los de derecho patrio. Sobre latinidad no se especificó nada.

Para pasar a la siguiente cátedra, los alumnos serían examinados durante una hora por el profesor en quien recaería la aprobación del examinado, luego lo entregaría al profesor de la siguiente materia, la

\footnotetext{
${ }^{9} \mathrm{El}$ reglamento se formó atendiendo al punto siete del decreto del 19 de octubre del 1833, donde se establecía que la dirección formaría todos los reglamentos de enseñanza y gobierno económico de cada uno de los establecimientos y los pondría en ejecución. Obviamente la dirección no podía encargarse de todo y por ello delegó la tarea a las autoridades de los establecimientos como se estipuló en la ley del 23 de octubre.
} 
prueba sería presidida por el director, quien tendría voto de calidad. Seguramente este punto se incluyó porque los alumnos, según palabras de Espinosa de los Monteros, se habían "creído con derecho para pasar de unas a otras cátedras", como se hacía anteriormente (BUT, CB, JMLM: f. 241).

La instrucción teórica de los alumnos se complementaría con la práctica, la cual debía realizarse todos los días de cuatro a siete de la tarde en el despacho de algún abogado acreditado. Esta obligación se aplicaría a los estudiantes que iniciaran el curso de derecho político constitucional y terminaría al concluir la segunda cátedra de derecho patrio. $\mathrm{Al}$ finalizar su práctica, el abogado les extendería una certificación, la cual serviría al alumno para examinarse de esa profesión.

La prueba, como se estableció en el tercer punto del documento de Garza, se efectuaría por los profesores del establecimiento previa orden de la dirección general. A dicho órgano, los candidatos presentarían una petición donde acreditaran la conclusión de todos los cursos y la práctica, dada la autorización para examinarse, el interesado asistiría tres días antes del examen para la asignación de puntos, dos corresponderían a las Siete Partidas de la tercera en adelante, ${ }^{10}$ y uno a la Novísima Recopilación de las Leyes de España, a partir del décimo libro. ${ }^{11} \mathrm{El}$ alumno seleccionaría uno de los puntos y realizaría una exposición menor a los 30 minutos, después se le evaluaría de los tres puntos por igual número de profesores durante media hora cada uno.

El acto sería presidido por el director, quien tendría voto de calidad y los profesores contarían con voto simple. La calificación otorgada sería secreta y se asentaría de la siguiente forma: AA para los aprobados y RR para los reprobados, los resultados se enviarían a la dirección general. Los alumnos aprobados presentarían ante ésta un juramento y la dirección ordenaría la expedición del título de abogado; este punto fue aprobado el 15 de enero de 1834 (El Fénix de la Libertad, 15/I/1834, t. IV, núm. 15: 4). La asignación de puntos era una práctica realizada desde la época virreinal tanto en la universidad como en los colegios, aunque los libros de donde se asignaban los puntos eran totalmente diferentes, en cánones se elegían de las Decretales y el Decreto y, en leyes, del $D i$ gesto Viejo y del Código.

El mismo procedimiento se realizaría para los exámenes de doctor, pero los puntos se abrirían en los autores explicados en tres cátedras elegidas mediante la suerte. Los profesores fungirían como examinadores y preguntarían hasta quedar satisfechos de la instrucción del aspirante. Terminado el examen, los miembros de la dirección recibirían el juramento del candidato en forma pública, en el general del establecimiento, luego le pondrían un anillo en señal del grado y, por último, le conminarían a subir a la cátedra para pronunciar un discurso de agradecimiento. Algunos de los actos protocolarios guardaban similitud con los seguidos por los recién doctorados en la Real Universidad de México, a ellos también se les entregaba un anillo, subían a la cátedra y hacían un juramento, no obstante, la graduación de doctor en el periodo analizado eliminó todo aquello relacionado con la participación de la Iglesia, así pues, la obtención de dicho título se secularizó.

\footnotetext{
${ }^{10}$ Las partidas buscaban crear un código jurídico unificado en Castilla. La III partida trata sobre derecho procesal, agentes judiciales, pruebas, sentencias, apelaciones y ejecución de dichas sentencias; la IV se refiere a temas familiares como los matrimonios, filiación, tutela de los menores; asimismo, regula la relación entre el amor, los sirvientes, criados, la amistad y el vasallaje; la V se ocupa de los préstamos, contratos comerciales, compras y deudas; la VI versa sobre testamentos, herencias, devoluciones y tutela de bienes de menores; la VII alude al derecho penal, a los delitos sexuales como sodomía, rapto, adulterio e incesto y a otras trasgresiones como la blasfemia, adivinación, sacrilegio y hechicería; se señalan los castigos, tormentos y prisiones del reo.

${ }^{11}$ La Novísima fue elaborada por el jurista Juan de la Reguera por decreto de Carlos IV, se trata de una recopilación del derecho castellano y español. Su confección responde a las corrientes codificadoras de la ilustración, está conformada por 12 libros y 340 títulos. El libro 10 se ocupa del derecho civil, el 11 del derecho procesal y el 12 del derecho penal.
} 
En el informe de Espinosa del 16 de abril, éste hacer saber que algunos alumnos ya se habían presentado a los exámenes — no se indica cuándo, ni si lo hicieron siguiendo lo establecido en el reglamento - y "no han dejado que desear en casi la totalidad de los examinados. Este mismo suceso hace esperar en las calificaciones sucesivas, el gusto con que los oyentes han recibido la nueva enseñanza" (BUT, CB, JMLM: f. 240). Lo anunciado por el director del establecimiento autoriza a señalar que las reformas habían logrado en menos de cinco meses introducir algunos cambios, aunque con ciertos tropiezos, pues varios alumnos habían intentado seguir prácticas antiguas y no todos se habían examinado. Lo dicho por este personaje disiente de lo expuesto por Casimiro Liceaga, director del establecimiento médico, quién en su informe de abril de 1834, aseguro que el desempeño de los alumnos en el examen general había sido pésimo (BUT, CB, JMLM, f. 281).

El último decreto relativo a los establecimientos fue expedido por la dirección general el 2 de julio de 1834, cuando Santa Anna ya había regresado a la presidencia (24 de abril), motivado por el malestar provocado por el destierro de algunos ciudadanos, las reformas anticlericales y por la epidemia de cólera morbus. Se trata de un reglamento para "sistematizar la instrucción"; en la sección cuarta de la ley se dispuso un nuevo orden para los estudios, en el caso de Jurisprudencia se determinó la existencia de diez cátedras, es decir, las asentadas por Espinosa en su informe con dos variaciones, se suprimió la palabra civil en la asignatura de derecho romano y elocuencia sólo se consignó como forense en lugar del foro y la tribuna.

Sin duda, el cambio más importante del reglamento fue el de organizar las cátedras por años y ya no por horarios, así en el primer año se daría derecho natural de gentes y marítimo, en el segundo derecho romano y canónico, en el tercero las mismas asignaturas, más derecho patrio, en cuarto segundo de patrio con ejercicios de práctica forense y en el quinto se continuaría con derecho patrio, los ejercicios indicados y elocuencia forense. La cátedra de ética podría añadirse a cualquiera de los cursos anteriores; sobre latinidad nuevamente no hubo especificaciones. La duración de las lecciones sería de dos horas para latinidad, hora y media para práctica forense y ejercicios y una hora para las demás cátedras (Talavera, 1973: 202-203 y 205). Las trasformaciones respondían a lo planteado en los decretos de 1833.

Otro aspecto ligado a la enseñanza es el relativo a los autores y textos, en el caso de los exámenes para abogado, estos fueron establecidos, pero ¿cuáles se empleaban para las cátedras? Hasta el momento no ha sido posible precisarlo, ya que ni en las fuentes documentales, ni en los periódicos de la época se registran, como si sucedió con otros establecimientos, no obstante, podrían sugerirse algunos teniendo en cuenta lo planteado en 1823 por José María Luis Mora en su memoria sobre reformas al plan de estudios del Colegio de San Ildefonso, éstos son: Recitaciones del derecho civil romano según la Instituta de Juan Teófilo Heinecio, Instituciones del derecho canónico de Domingo Cavallario, Curso de política constitucional de Benjamin Constant y Arte de la gramática latina de Calixto Hornero (Briseño et al., 1994a: 54-55), aunque también pudo utilizarse la Gramática latina de Juan de Iriarte empleada en el Establecimiento de Estudios Preparatorios. La selección hecha se debió a la existencia de ejemplares, bajo precio y buen método.

Para las otras materias pudieron seguirse la Ilustración del derecho patrio de España de Juan Sala, reimpreso en México entre 1831 y 1832 con añadiduras de doctrinas y disposiciones del derecho novísimo, del indiano y del mexicano hasta 1829, razón por la cual sólo llevaba de Sala el nombre. También pudo emplearse Derecho de gentes o principios de la ley natural aplicados a la conducta y a los asuntos de las naciones y de los soberanos de Emerick de Vattel, obra que era vendida en algunas librerías de la ciudad, o Elementos de la legislación natural de Perrau o Perró. Varios textos fueron seguidos en México desde finales del siglo XVIII y hasta por lo menos la primera mitad del XIX, debido a 
la inexistencia de libros escritos por mexicanos, pero adaptándolos a la realidad jurídica del naciente país (Arenal, 1998: 33). Sobre la asignatura de práctica del foro y la tribuna, quizá se siguió el Apéndice al manual de Práctica Forense de D. Eugenio de Tapia elaborado por Anastasio de la Pascua y publicado en 1830; de la cátedra de ética no se tienen noticias sobre el posible texto utilizado. La selección de autores en cuanto a nacionalidad fue variada, aunque predominaron los españoles, sin faltar textos ya clásicos como los de Heinecio y Salas.

Como se puedo observar, la principal innovación en el programa de estudios de Jurisprudencia se dio en la inclusión de diferentes ramas del derecho antes no estudiadas en el Colegio de San Ildefonso o en la propia Universidad de México, donde los derechos reinantes eran el romano y el canónico. Respecto a los textos empleados, si bien podrían parecer poco novedosos, éstos, como ya se dijo, fueron reeditados con retoques y ampliaciones para adecuarlos lo más posible a los nuevos tiempos. Con relación a lo que se deseaba enseñar a los estudiantes se ha encontrado, por ejemplo, la decisión tomada por la comisión del plan de estudios en su sesión del 10 de octubre de
1833 respecto a la cátedra de derecho patrio, que según la junta debía contemplar el "estudio de derecho civil, mercantil, criminal y marítimo, vigentes en la actualidad" (AGN, IPBA, caja 37, exp. 29, f. 307). Derecho marítimo y civil sí quedaron asentados como materias, sobre el criminal y marítimo no se sabe si se enseñaron en la cátedra de patrio.

Sobre los métodos de enseñanza, Mora lamenta la falta de grandes innovaciones, las cuales indica no pudieron hacerse por dos razones: no hubo tiempo para efectuarlas y no eran lo suficientemente conocidas, a diferencia de Europa donde se practicaban (Briseño et al., 1994b: vol. 2, 475), desgraciadamente no da cuenta de cuáles eran esos métodos.

\section{Profesores y alumnos}

La dirección general se encargaría de nombrar a los profesores la primera vez, según la ley se haría a propuesta en terna de los directores de cada establecimiento y, posteriormente, mediante un concurso de oposición. La tarea de instrucción a los alumnos del quinto establecimiento recayó en los siguientes personajes, según se consignó en el periódico El Fénix de la Libertad (cuadro 1).

\section{Cuadro 1. Profesores y cátedras}

\begin{tabular}{|c|c|}
\hline Profesor & Cátedra \\
\hline Bernardo Couto & Derecho romano \\
\hline José María Jáuregui & Derecho canónico \\
\hline Simón de la Garza & Derecho político constitucional \\
\hline José María Puchet & Primera de derecho patrio \\
\hline José Sotero Castañeda & Segunda de derecho patrio \\
\hline Manuel Crescencio Rejón & Derecho natural de gentes y marítimo \\
\hline José María Guzmán & Retórica \\
\hline Manuel Chávez & Primera de latín \\
\hline José María Estrada & Segunda de latín \\
\hline
\end{tabular}

Fuente: El fénix de la libertad, 26/XII/1833, t. III, núm. 148: 2. 
A esta lista debe agregarse a Anastasio de la Pascua, quien fue nombrado profesor de ética, además de sustituir la cátedra de derecho natural, sin embargo, no se puede aclarar debido a la falta de información, la fecha de su designación como catedrático, ni tampoco el cuándo y el por qué empezó a sustituir a Crescencio Rejón, posiblemente lo hizo por las ocupaciones de Rejón dentro de la dirección general (AHUNAM, FCSI, Rectoría, vida académica, Junta de Catedráticos, caja 47, exp. 3, doc. 8, f. 50r).

De los profesores elegidos, cuatro ocuparon el mismo cargo en San Ildefonso, los teólogos José María Estrada y Manuel Chávez impartían latín y el también teólogo José María Guzmán, retórica: los tres fueron contratados en la misma asignatura dada cuando el colegio fue clausurado, mientras que el teólogo Simón de la Garza había dejado, después de una larga carrera como profesor, la cátedra de teología en 1825, pero seguía presente en la institución ildefonsiana, a este personaje se le dio la cátedra de derecho político constitucional, lo cual podría resultar extraño, no obstante, Garza había cursado jurisprudencia, pero sin obtener el grado. La recontratación de catedráticos no fue exclusiva del establecimiento jurídico, pues como ha observado Cristian Rosas, dos profesores del Colegio de Letrán continuaron en el de ciencias eclesiásticas (Rosas, 2019: 87). El resto de los profesores de jurisprudencia habían estudiado derecho canónico y civil en el colegio y habían ocupado u ocupaban puestos en la administración pública. Finalmente se debe señalar que entre los catedráticos encontramos tanto a religiosos como a seculares.

Con relación a los alumnos, la documentación localizada sobre el quinto establecimiento no ha arrojado datos sobre el número de inscritos en él, pero se consideró un aproximado de 47 , cantidad no tan alejada de los estudiantes de otros establecimientos; en ciencias eclesiásticas había 46, en ciencias médicas, 24, en ciencias físicas y matemáticas 39 (Rosas, 2015: 115 y 149; Rosas, 2019: 94) y en estudios preparatorios 56 (BUT, CB, JMLM: f. 273). No se sabe por el momento el número de cursantes en el Establecimiento de Estudios Ideológicos.

Para inscribirse a los estudios jurídicos los aspirantes debían cursar de forma previa, según la ley del 23 de octubre, dos cátedras de latinidad y un curso de francés, otro de elementos de aritmética, álgebra, geometría y lógica, uno de ideología, así como de moral natural (Dublán, 1876: 573). Seguramente muchos de los alumnos inscritos no contaban con tales estudios, pues aquellos pertenecientes a San Ildefonso solo pudieron cursar en él latín y los provenientes de otras instituciones no contaban, por lo menos, con los estudios de moral natural.

Los candidatos a ingresar al establecimiento podían hacerlo pagando una pensión de 160 pesos anuales o mediante pensiones de gracia provenientes de los antiguos colegios; su número total, contando las de todas las instituciones era de 94, pero como indicaba Gorostiza en su informe, sólo se había proveído una tercera parte de ellas. Para la provisión de las pensiones, señalaba el vicerrector Garza en los puntos propuestos para hacer el reglamento de jurisprudencia, el director debía presentar ante la dirección general una terna de donde se elegiría un alumno. Las pensiones no podrían trasladarse a otro establecimiento, aunque vacaran; éstas darían a los favorecidos las mismas cosas otorgadas a los alumnos que pagaban pensión completa, pero no se especifica qué cosas. La gracia duraría hasta la conclusión de la carrera literaria "a juicio de la Direccion general, a quien lo hará presente el Director del establecimiento en que concluyan", la gratificación se suspendería por la dirección si el alumno tenía mala conducta moral o escasa aplicación en los estudios, previo informe del director (BUT, CB, JMLM, f. 1r.). En el Establecimiento de Jurisprudencia y en otros tres, las pensiones sólo cubrían los alimentos a diferencia de estudios preparatorios, donde las pensiones eran altas, ya que los alumnos eran mantenidos de todo a todo, el monto de dichas pensiones ascendía a más de 30000 pesos anuales. 
A los alumnos, además de enseñárseles las diferentes ramas del derecho, también se les debía inculcar una educación disciplinaria y doméstica, así como prácticas religiosas. La inclusión de obligaciones religiosas tenía como finalidad, según expresa Mora, "reglar la conducta de un hombre en el mundo"; tales prácticas, a diferencia de lo sucedido con anterioridad en los colegios, no iban más allá de los deberes correspondientes al "común de los cristianos" (Briseño et al., 1994b: 470).

En los ya citados puntos para el reglamento, se hace referencia a tales rutinas, éstas consistirían en concurrir diariamente a la misa celebrada en el establecimiento, asistir por la noche a rezar el rosario o realizar alguna práctica devota establecida por el director. Asimismo, tanto los alumnos como los dependientes debían confesarse y comulgar cada año en la parroquia, sobre la comunión se agregaba la asignación por parte del director de algunos días del año para realizar ese sacramento, especialmente en las festividades principales destinadas por la Iglesia para Jesucristo y la Virgen María (BUT, CB, JMLM: f. 267).

La inculcación de prácticas religiosas, disciplina y educación doméstica junto con la enseñanza de las diferentes ramas del derecho que estaban en boga, intentaba que en el establecimiento jurídico se cumpliera con lo imaginado por el director Espinosa, proveer a los alumnos de una instrucción sólida y completa.

\section{A manera de conclusión}

La reforma educativa de 1833 o Revolución como la llamó José María Luis Mora, fue el primer proyecto que logró ponerse en marcha en el Distrito Federal, pero sin alcanzar los resultados esperados como se pudo advertir al revisar lo sucedido en el Establecimiento de Jurisprudencia. Las razones de su aplicación moderada se debieron a factores económicos, a la multitud de actividades a desarrollar por un puñado de hombres, a la oposición de sectores ajenos a los establecimientos, pero también a la propia resistencia de los alumnos, sin olvidar un hecho sumamente importante, la supresión de todas las medidas a tan sólo seis meses de haber iniciado las actividades de los establecimientos.

No obstante, se lograron hacer algunos cambios, siempre apegados a los decretos emitidos y atendiendo a su función principal, así fue posible introducir conocimientos básicos y necesarios para la formación de los abogados, los cuales resultaban útiles no sólo para cubrir las necesidades legislativas y legales del naciente país sino también para enfrentar los retos de una nación que abría sus puertas al ámbito internacional. Las reformas también tuvieron como finalidad la formación de individuos moralmente intachables, disciplinados y religiosos, aunque su manera de trasmitir la religiosidad fue un tanto diferente a la inculcada con anterioridad, servir a Dios seguía siendo importante, pero lo era más servir a la nación.

En materia financiera la situación del quinto establecimiento resultó un tanto ambigua, pues con sus ingresos parecía que podían cubrirse todas las cargas, sin embargo, los adeudos tanto a individuos fuera de la institución como dentro de ella fueron mayores, impidiendo así la realización de algunos proyectos para la mejora del edificio o contando con recursos escasos para dar pensiones a los alumnos. El financiamiento de Jurisprudencia, al igual que el de los demás establecimientos, fue de tipo mixto como ha apuntado Cristian Rosas, éste no sólo provenía de los fondos del colegio de San Ildefonso, sino también de la hacienda pública.

Las reformas de 1833-1834 aplicadas al Establecimiento de Jurisprudencia, permiten observar varios rasgos secularizadores entre los que destacan la desaparición del carácter corporativo sustentado antiguamente en los colegiales, quienes dejaron de ser personajes privilegiados y se convirtieron en meros estudiantes. Otro cambio observado fue el de sustituir al rector eclesiástico por un director laico, si bien en la subdirección, anteriormente vicerrectoría, un 
eclesiástico continuó en el cargo; también siguieron en sus puestos profesores seculares, aunque se tendió a favorecer a los seglares con un perfil más político que religioso. Por último, es posible advertir en varios momentos el control ejercido por el Supremo Gobierno, especialmente en la forma de examinar, en los libros y autores a utilizar, en el financiamiento y en lo acontecido al interior de él.

Los avances, cambios y tropiezos experimentados en el quinto establecimiento, como pudo observarse, no fueron exclusivos de éste, las otras instituciones también atravesaron dificultades, ello faculta para decir que pese a contar en el papel con una reforma bien planeada y estructurada, la realidad fue distinta debido a problemas financieros, disputas entre

\section{Referencias}

Alvarado, Lourdes (2005), "El claustro de la Universidad ante las reformas educativas de 1833", en Enrique González González y Leticia Pérez Puente (coords.), Permanencia y cambio I. Universidades hispánicas, 15512001, México, CESU-UNAM/Facultad de Derecho, pp. 277-291.

Alvarado, Lourdes (2003), "La Universidad de México ante el embate del liberalismo (1833-1865)", en Miscelánea Alfonso IX 2002, Salamanca, Centro de Historia Universitaria-Universidad de Salamanca, 2003, pp. 167-182.

Arenal Fenochio, Jaime (1998), "Ciencia jurídica española en el México del siglo XIX”, en La supervivencia del derecho español en Hispanoamérica durante la época colonial, México, Instituto de Investigaciones Jurídicas-UNAM, pp. 31-47.

Briseño Senosiain, Lilian, Laura Solares Robles y Laura Suárez de la Torre (investigación, recop. y notas) (1994a), José María Luis Mora. Volumen 1. Obra política I, México, Instituto Mora/CONACUlTA.

Briseño Senosiain, Lilian, Laura Solares Robles y Laura instituciones, excesiva carga de trabajo de los directores y de los miembros de la dirección general, reticencia de los alumnos a los cambios, personajes no comprometidos con las trasformaciones o individuos vendidos al mejor postor para no perder sus privilegios, entre otros motivos.

En una futura investigación será necesario revisar las cuentas subsecuentes al año de 1834 con la finalidad de conocer el estado financiero real del Establecimiento de Jurisprudencia e indagar más sobre los profesores y sobre el contenido de la enseñanza, además de reflexionar sobre el grado de secularización alcanzado en el establecimiento y sobre las continuidades entre el antiguo y nuevo régimen, algunas ya han sido indicadas en el texto.

Suárez de la Torre (investigación, recop. y notas) (1994b), José María Luis Mora. Volumen 2. Obra política II, México, Instituto Mora/CONAGULTA.

Costeloe, Michael P. (1996), La Primera República Federal de México (1824-1835). Un estudio de los partidos políticos en el México independiente, México, FCE.

Pavón Romero, Armando, Yolanda Blasco-Gil y Luis Enrique Aragón-Mijangos (2013), “Cambio académico. Los grados universitarios. De la escolástica a los primeros ensayos decimonónicos", Revista Iberoamericana de Educación Superior, vol. IV, núm. 11, pp. 61-81. <https://www.ries.universia.unam.mx/ index.php/ries/article/view/100/393> [Consulta: noviembre de 2018].

Ramos Escandón, Carmen (1994), Planear para progresar: planes educativos en el México nuevo, 1820-1833, México, UPN.

Ríos Zuñiga, Rosalina (2016), "La transición hacia los estudios "medios y superiores", y la Nacional y Pontificia Universidad durante las primeras décadas del México independiente (1821-1856)", en Hugo 
Casanova Cardiel (coord.), La UNAMy su historia. Una mirada actual, México, IISUE, 2016, pp. 121-149.

Ríos Zúñiga, Rosalina (1994), "De Cádiz a México. La cuestión de los institutos literarios (1823-1833)", Secuencia. Revista de Historia y Ciencias Sociales, núm. 30, sept-dic, pp. 5-32.

Rosas Íñiguez, Cristian (2019), "El Establecimiento de Ciencias Eclesiásticas de la ciudad de México. ¿Avances hacia la laicización educativa? (1833-1834)", en Adelina Arredondo (coord.), La educación laica en México: estudios en torno a sus orígenes, México, UAE/ Bonilla Artigas Editores, pp. 71-106.

Rosas Íñiguez, Cristian (2015), La educación de médicos e ingenieros en la reforma educativa de la ciudad de México, 1833, 1834, México, Facultad de Filosofía y LetrasUNAM.

Sánchez Santiró, Ernest (2008), "Nación, república y federalismo: las transformaciones de la Universidad de México y su impacto en los estudios de filosofía, 1821-1854”, en Enrique González González (coord.), Estudios y estudiantes de filosofía. De la Facultad de Artes a la Facultad de Filosofía y Letras (1551-1929), México, IISUE/FFyL-UNAM/COLMICH, pp. 365-403.

Talavera, Abraham (1973), Liberalismo y educación. Tomo I, México, Secretaria de Educación Pública.

Tanck de Estrada, Dorothy (1971), "Las Cortes de Cádiz y el desarrollo de la educación en México", Historia Mexicana, vol. 29, núm. 1, julio-sept, pp. 3-34.

\section{Fuentes documentales}

Archivo General de la Nación (AGN), Ramos Justicia e Instrucción Pública (JIP) e Instrucción Pública y Bellas Artes (IPBA).

Archivo Histórico de la UNAM, Fondo Colegio de San Ildefonso (FCSI).
Biblioteca de la Universidad de Austin, Texas (BUT), Colección Latinoamericana Nettie Lee Benson (CB), Archivo José María Luis Mora (JMLM).

\section{Fuentes hemerográficas}

El Fénix de la Libertad, 1833.

El Indicador de la Federación Mexicana, 1834.

\section{Impresos}

Dublán, Manuel y José María Lozano (1876), Legislación mexicana o colección completa de las disposiciones legislativas desde la independencia de la república. Tomo II, México, Imprenta del Comercio.

Constitución Federal de los Estados Unidos Mexicanos (2005), <https://archivos.juridicas.unam.mx/www/bjv/ libros/4/1671/35.pdf > [Consulta: septiembre de 218].

Memoria de la Secretaria de Estado y del Despacho de Relaciones Interiores y Exteriores: leída por el Secretario del ramo en la Cámara de Diputados el día 12 febrero de 1830, y en la de Senadores el día 13 del mismo, (1830), <https://archive. org/details/b29294137/page/46> [Consulta: octubre de 2018].

Memoria de la Secretaria de Estado y del Despacho de Relaciones Interiores y Exteriores presentada por el secretario del ramo a las cámaras del Congreso general, en cumplimiento del artículo 120 de la constitución y leída en la de diputados el día 7 y en la de senadores el 8 de enero de 1831 (1831) <https://archive. org/details/b29294113/page/n7> [Consulta: octubre de 2018].

Reglamento general de instrucción pública, decretado por las Cortes, en 29 de junio de 1821 (1821), Coruña, Imprenta de Arza.

Reglamento provisional politico del Imperio mexicano (1823), <https: / / archivos.juridicas.unam.mx/www / legislacion/federal/historicos/regprov.pdf> [Consulta: septiembre de 2018].

\section{Cómo citar este artículo:}

Hidalgo-Pego, Mónica (2020), "La primera reforma educativa liberal y su implementación en el Establecimiento de Jurisprudencia. Distrito Federal, 1833-1834", Revista Iberoamericana de Educación Superior (RIES), vol. XI, núm. 31, pp. 86-103, DOI: https://doi. org/10.22201/iisue.20072872e.2020.31.707 [Consulta: fecha de última consulta]. 